\title{
Evaluation of satisfaction rate of dental implants in patients referred to private clinics of Kermanshah city
}

\author{
Hedaiat Moradpoor ${ }^{1}$, Amir Hossien Moradi², Sara Taherzadeh ${ }^{3}$ and Sahar Raissi ${ }^{4 *}$ \\ ${ }^{1}$ Assistant Professor, Prosthodontics Department, Faculty of Dentistry Kermanshah University of Medical \\ Sciences, Iran \\ ${ }^{2}$ Assistant Professor, Prosthodontics Department, Faculty of Dentistry Kermanshah University of Medical \\ Sciences, Iran \\ ${ }^{3}$ Faculty of Dentistry Kermanshah University of Medical Sciences, Iran \\ ${ }^{4}$ Assistant Professor, Prosthodontics Department, Faculty of Dentistry Kermanshah University of Medical \\ Sciences, Iran
}

\begin{abstract}
The satisfaction of dental care has always been an important topic in the field of dentistry. Several studies in the country from different parts of the dental patient satisfaction has been made. But few specific studies on the satisfaction of patients of the dental implant have been done. This study was aimed to assess the satisfaction of implantation done in the city of Kermanshah. Since the present study, is a retrospective study, 108 cases of dental implants placed in selected patients were asked to fill a questionnaire that included demographic information and questions related to the satisfaction of dental implants placed were asked. Data were collected and analyzed using software SPSS18 were analyzed. The results showed that the level of patient satisfaction in the satisfaction of the cost, 80\%above the average and 9.7 is weak. Patients' satisfaction with the performance of, and only 2.7 percent of the poor were good average 3/97. The findings also showed that mental satisfaction and overall satisfaction of patients was 100\%.But the satisfaction of performance including waiting time was less than the satisfaction rate of 51 percent good and 49 percent were poor.
\end{abstract}

KEY WORDS: FELDSPATHIC PORCELAIN, IPS E.MAX HEAT PRESS LAYERED, ENAMEL TOOTH WEAR

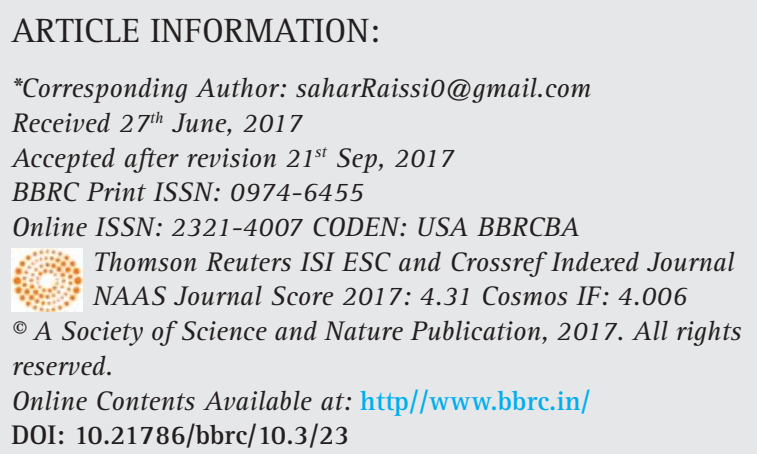




\section{INTRODUCTION}

Despite the many advantages that conventional prosthetics have in restoring the beauty and oral function of patients, their deficiencies cause dissatisfaction of patients in many cases, and this leads patients to tend to use more durable and more satisfying treatments, one of which is dental implants. The lack of serious defects and the problems of moving and fixed prosthesis, such as damage to adjacent teeth, Ridge jawbone fracture, undesirable beauty, and other defects in conventional prosthesis by replacement of bone implants have increased their usage worldwide, so that the use of dental implants in the United States has grown ten times during 20021983 years (Annear et al 2005) and (Karoussis et al 2003) and (Behneke 2002). With the advent of the osteointegrationtheory in dentistry and proving that pure titanium in direct contact with the bone could provide a good support for replacing missing teeth, then it led to the introduction of dental implants (Wheeler 2003).

At first, dental implants were used to maintain the function of the patients, but later it was added to the beauty. Along with the supply of various implant systems, many clinical studies have been conducted to assess their durability rates. Edleau et al. (1981), in their 15-year review, reported success rates of $84 \%$ in upper jaw and 93\% in mandibles (Adell et al 1981). High success and benefits such as the lack of need for adjoining tooth cuttin and the prevention of alveolar bone fraction have led to an increase in the use of dental implants (Hobo 1997) and (Lekholm 1999) and (Lindquist et al 1997).

Following the protocol provided by Branemark is often recommended to succeed in achieving successful osonetic secretion (De Bruyn et al 1995). Saha et al. (2013) in a study questioned 403 people to assess the awareness rate of dental implants whilethe results showed that half of them had completely no information about the implant (Saha et al 2013). These studies are consistent with recent studies of the low level of data about dental implants (Awad et al 2013). The lack of accurate and true information is one of the reasons that increase the unrealistic expectations of patients, which reduces their satisfaction (Satpathy et al 2011). The aim of this study was to evaluate the satisfaction of dental implants in patients treated with dental implants.

\section{MATERIAL AND METHODS}

In this analytical-descriptive study, in order to evaluate the satisfaction of implantation, 108 archival records of patients treated with dental implants were randomly selected using a randomized table referring to dental clinics in Kermanshah. In order to collect the research data, the researcher completed a questionnaire including demographic data and researcher made questions to assess the satisfaction of dental implant implantation by calling the patients and inviting them to face-to-face interviews. The scores of the questionnaire were ranked based on three good/medium/bad grades, which 1-2 as weak, 3-6 as average and 7 to 10 as good were ranked. Also, 1-2questions evaluate cost satisfaction; 3-6 questions evaluate satisfaction from implant function, and questions 7-10 assess mental satisfaction and satisfaction with the stages of work. Mental satisfaction is one of the modes of satisfaction (Levi et al 2003), which is calculated based on the score that a person received from the mental satisfaction questionnaire of the research questionnaire from questions 7 to 9 .

The study population was selected from patients treated with dental implants who had undergone at least one year of treatment. The sample size was calculated based on a pilot study and considering the variables of satisfaction such that $S=3.17$ (standard deviation), $\alpha=0.05$ (confidence), and $d=0.6$ (accuracy), while the minimum sample size was 108 , which was selected as convenience.

$$
n=\frac{Z_{1-\frac{a}{2}}^{2} S^{2}}{d^{2}}=107.229
$$

The collected data was analyzed by SPSS software version 18. In descriptive statistics, mean and frequency distribution and in inferential statistics, Mann-Whitney test were used.

\section{RESULTS}

The level of the cost satisfaction of the people was assessed $9.7 \%$ as weak, 47.8\% moderate, and 42.5\% as good.The satisfaction of individuals with implant function was evaluated as $2.7 \%$ weak, $4.4 \%$ moderate and $92.9 \%$ good. The mental satisfaction of individuals was evaluated as $0 \%$ weak, 16.8\% moderate and $83.2 \%$ good. The degree of satisfaction of the people from the stages of work was evaluated as $48.7 \%$ weak and 51.3\% good (Table 4-6 and Fig. 4-8). The satisfaction of beauty was evaluated 15\% were weak and $85 \%$ good. The satisfaction rate of the whole population was evaluated $0 \%$ weak, 10.6\% moderate and $89.4 \%$ good. The total satisfaction of the individuals by gender was evaluated in men, $0 \%$ weak, 10.6\% moderate and $89.4 \% \%$ good and in women $0 \%$ weak, 10.8\% moderate and $89.1 \%$ good.

In order to determine the relationship between satisfaction and age variables, implant loading years, gender and education level, Chi-square and Fisher's exact tests were used. Chi-square test showed no significant 


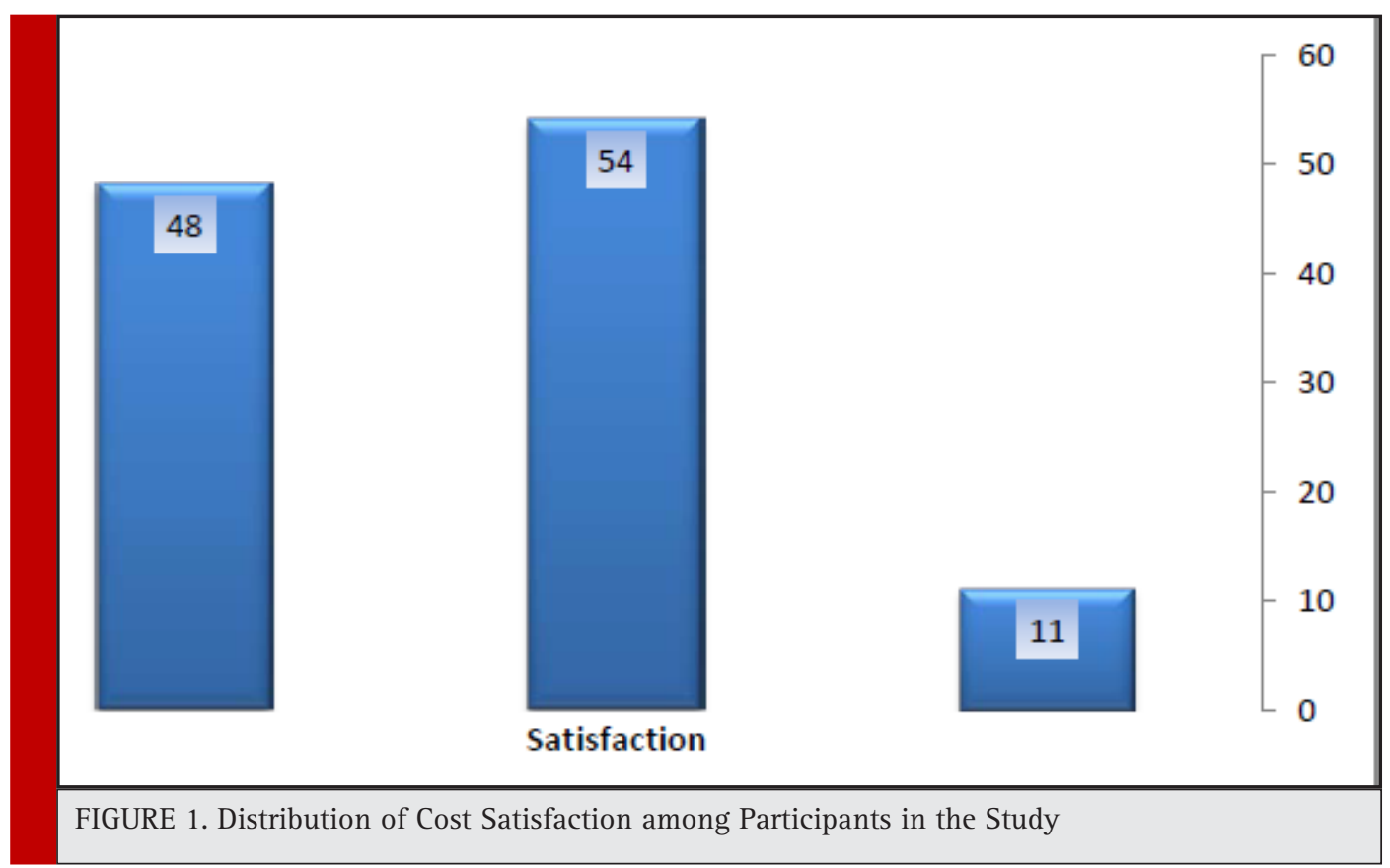

relationship between satisfaction and age (forty-five years or less - more than forty-five years) (P-value $=$ 33.93). Fisher's exact test showed no significant relationship between satisfaction and implant loading years (three years or less, more than three years) (P-value $=$ 513). Chi-square test showed no significant relationship between satisfaction and gender $(\mathrm{P}-\mathrm{value}=-0.96)$. Fisher's exact test showed that there was no statistically significant relationship between satisfaction level and level of education (diploma and undergraduate - university degree $(\mathrm{P}$-value $=0.96)$.

\section{DISCUSSION AND CONCLUSION}

Research findings in the area of satisfaction from the cost of implanting showed that almost ninety percent of

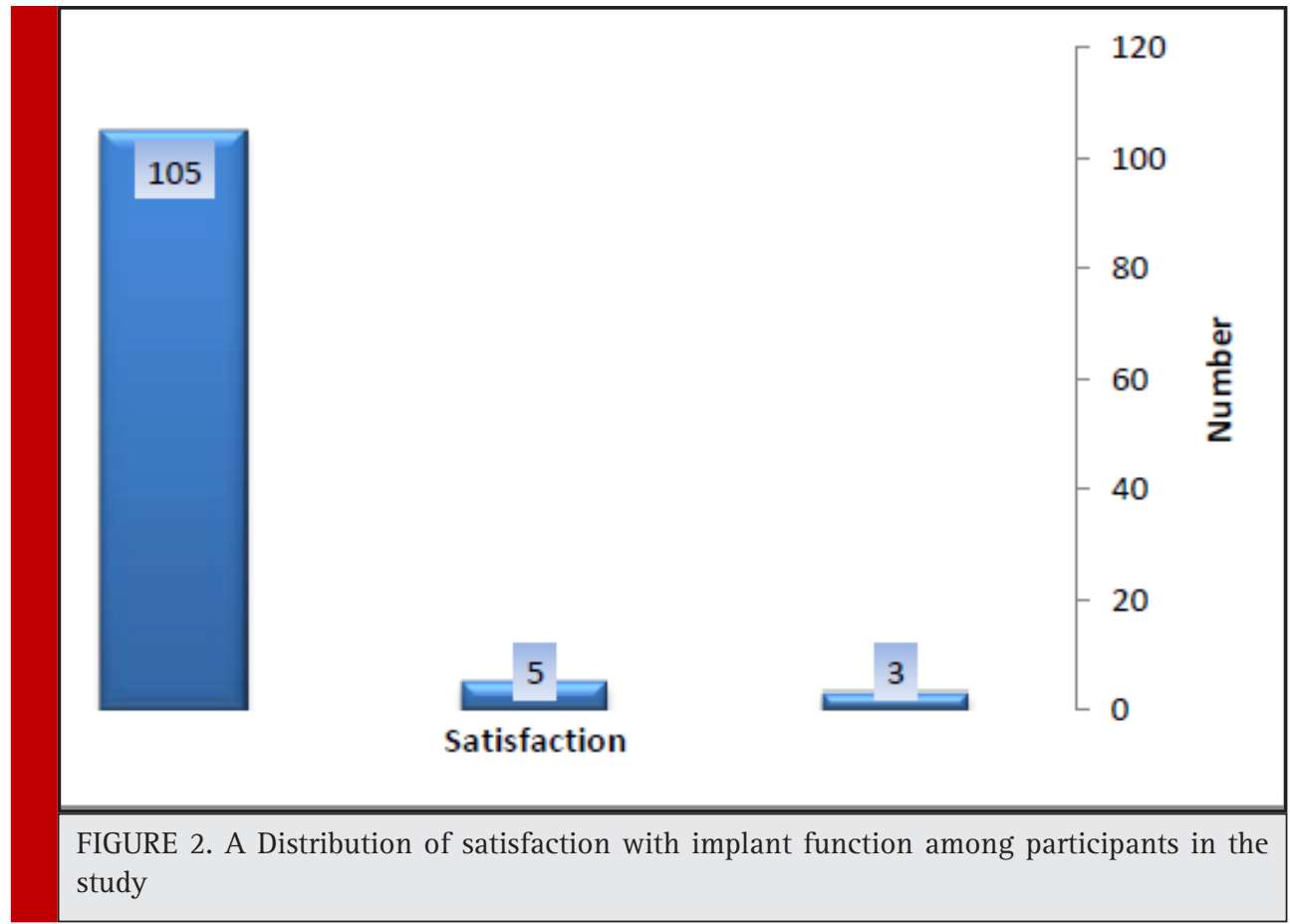




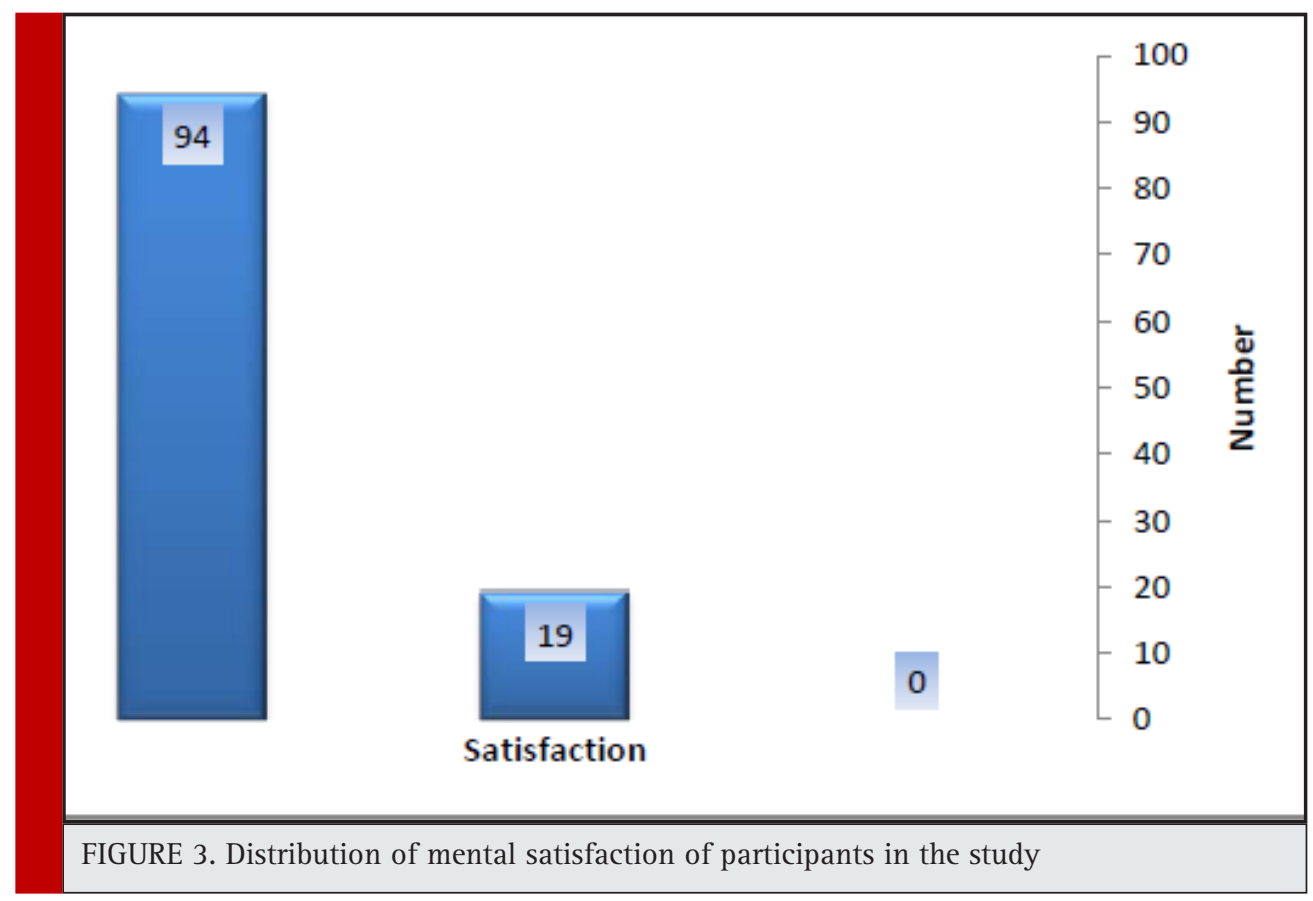

participants were satisfied with the cost of implanting. It is clear to everyone that the dental services in our country are expensive due to the cost of dental materials and its costs. Patients always expect the services to be satisfactory and cost-effective. The results of this study showed that the patients in this study were satisfied with the cost of implant implantation, which indicates that patients' expectations have been met. This means that although the inserted implant imposed cost on them, but it has been able to keep them satisfied with this action. The results of this study were consistent with the results of study by Rismanchian et al. (2007). The Rismanchian et al, in their study reported a satisfaction of over $90 \%$. In their study, 107 male and female patients were evaluated. Their study was a two-year study, but the current study was a one-year study after implant implantation,

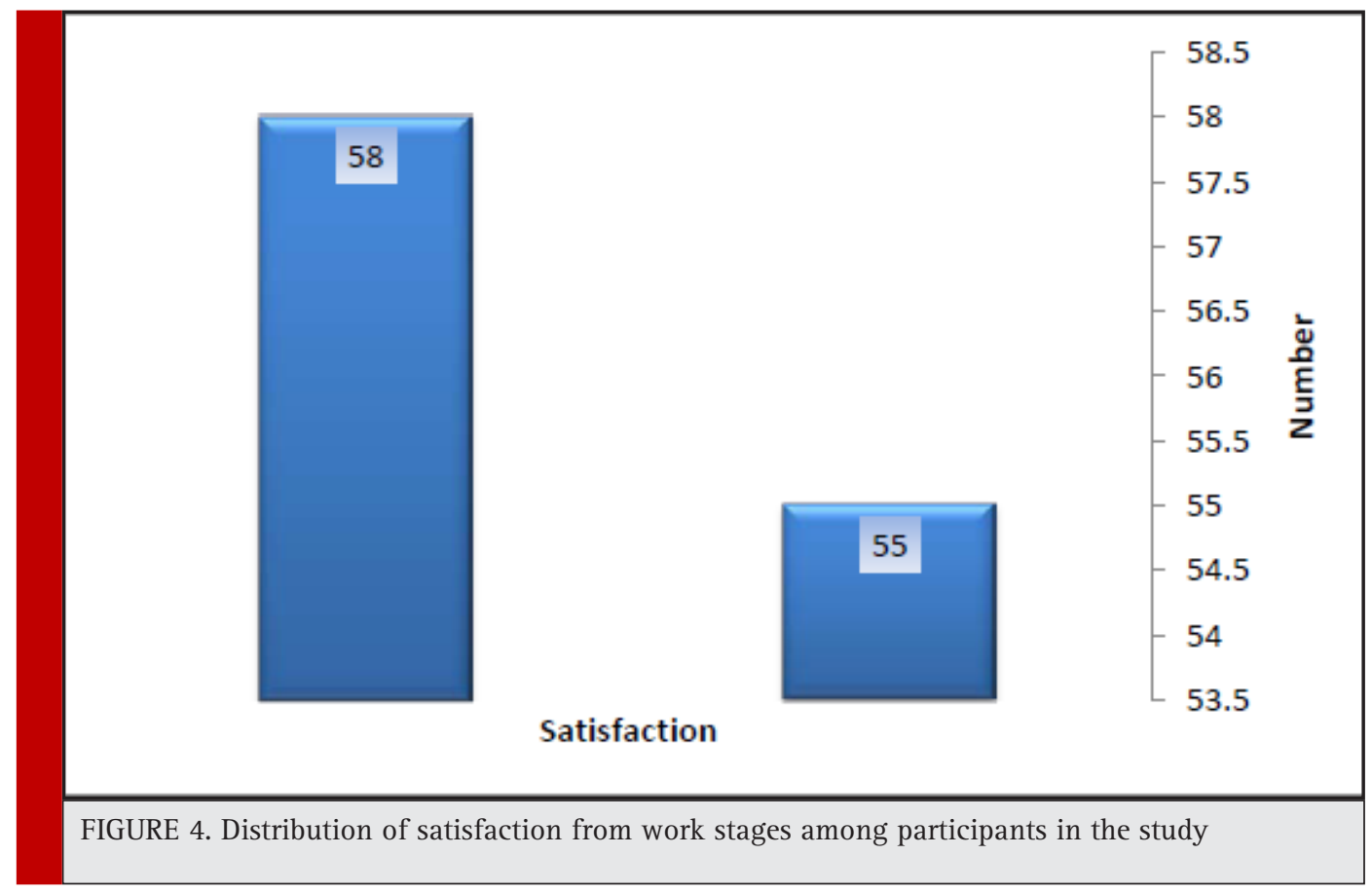




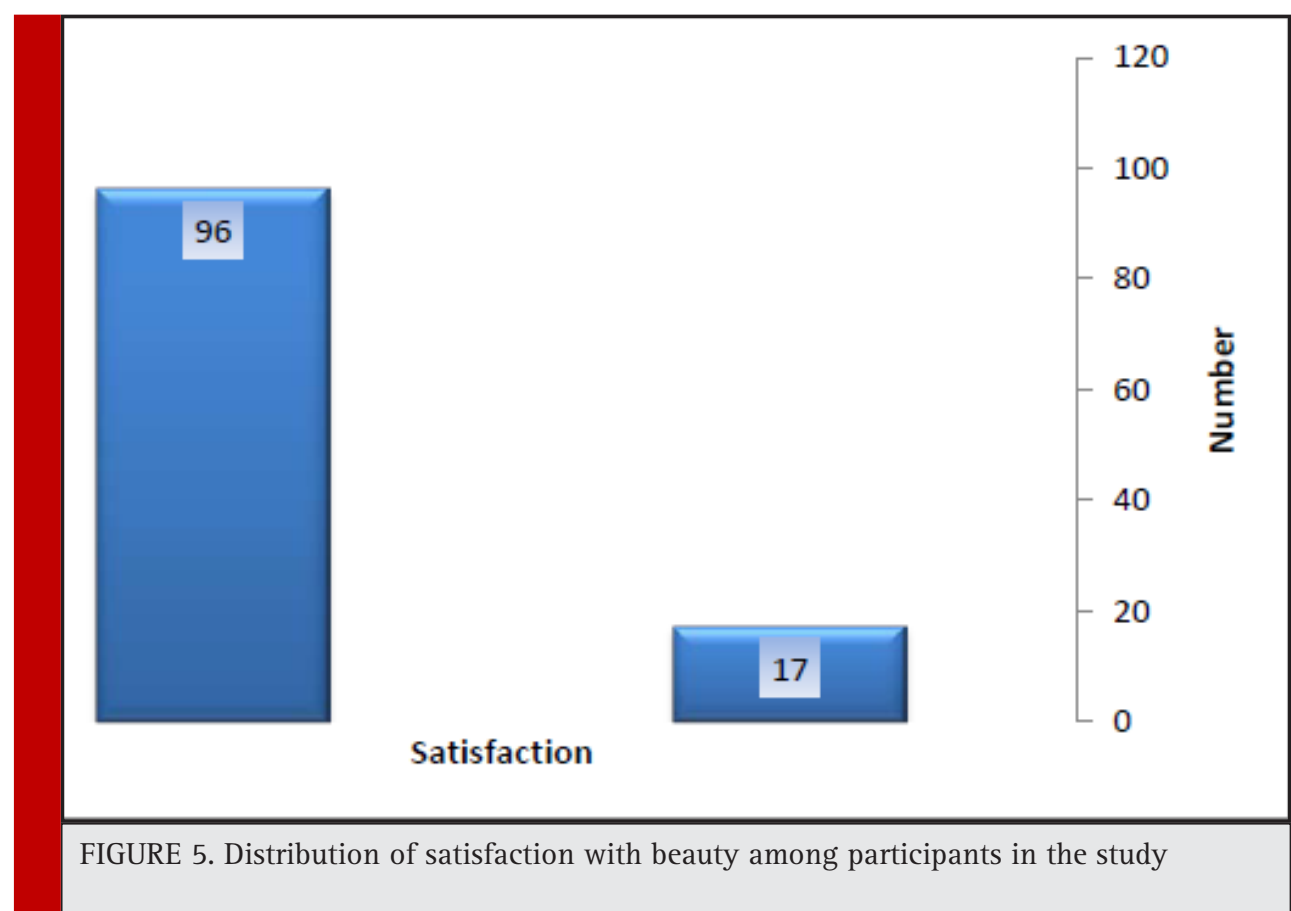

however, high satisfaction was reported in both of the mentioned studies.

The findings of the study showed that all individuals are satisfied with implanted implants. More than 92\% of the patients in the study showed a moderate to high satisfaction with implant function. Implant function is very important for the patient. The results of this study are consistent with the results of studies by Pjetursson et al (2005), Levi et al. (2003). They reported in their stud- ythat more than $90 \%$ of patients who have implants are satisfied with implant function. In studies ofPjetursson et al. (2005) implanting time was for 5 to 15 years. But the current study was a one-year study, but the results in both studies showed a high satisfaction of patients from implantation.

It is worth noting that Pjetursson et al. (2005) used VAS for measuring patients' satisfaction in their study, but in the current study, only a questionnaire was used

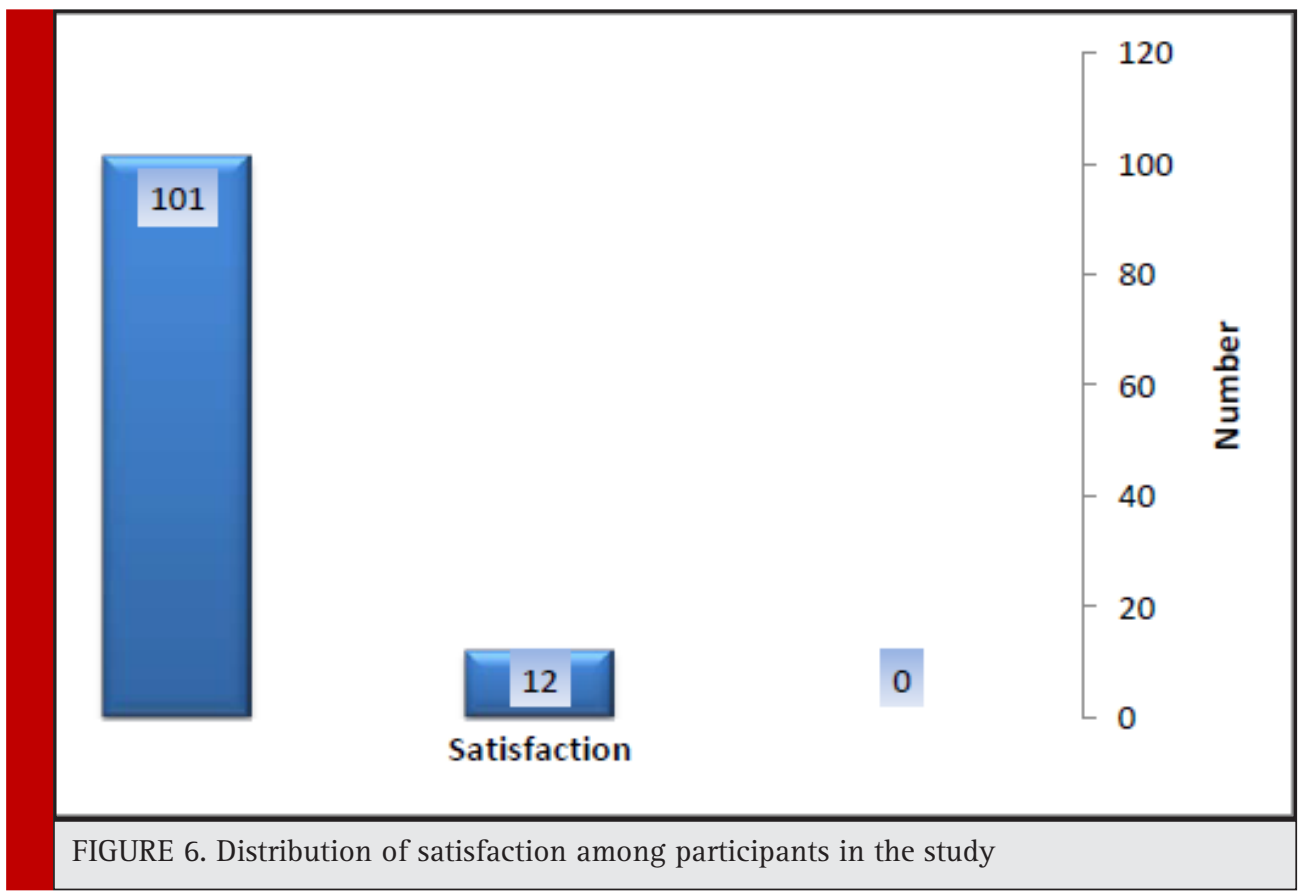


Pjetursson 2005). The primary purpose of the implant is to help the patient's function, and this goal is still important for patients. An implant satisfaction survey shows that satisfaction with implants is high in patients and it has been able to meet patient expectations (Jie Yao et al 2014). In their study, patients were satisfied with the condition of the implant, shape, overall appearance, effect on the speech, and the ability of the function. The results of the current study also confirm this satisfaction. Although satisfaction was used in their study using email, the degree of satisfaction in the current study was consistent with their study.

The findings of the research in the area of mental satisfaction showed that more than $80 \%$ of the patients had a high satisfaction with the implants, while the findings showed that only $16 \%$ of the patients had low mental dissatisfaction. Mental satisfaction is a condition in which a person is satisfied with the work done and has internal satisfaction (Levi et al2003), which is calculated, based on the score obtained from the mental satisfaction questionnaire of the research questionnaire, which are these questions 7-9. The results of this study were consistent with the results of Levi et al. (2003).

They reported in their study that patients who have dental implants had a high degree of mental satisfaction with their implants. Patient's mental satisfaction can reveal a set of person's satisfaction with cost, function, beauty. Patient mental satisfaction can be considered as the most important type of satisfaction, because if there is no mental satisfaction, it can be claimed that the work has failed. But given the fact that some patients have very high expectations from implants, their implant satisfaction is not provided after implantation. This can be argued that a dentist must reach the patient's expectations before implantation, and moderate the unreasonable mental expectations of the patient (Levi et al 2003). Patients are expecting miraculous treatments by referring to dental centers and hearing some of the new techniques. Dentists can make the patient's mental expectations largely acceptable with a simple explanation of the stages of work and problems that may occur during work.

The findings of the study showed that only half of the participants were satisfied with the stages of work, and the other half were completely dissatisfied with the work process. Dissatisfaction with the work process involved the waiting time until the layout of the cover. Dental services, and especially implants are usually time-consuming due to the collaboration of several specialists and labs, but the patient expects to achieve the goal at a very short time. It is necessary to the dentist explain the required steps to increase the patient's satisfaction, the need for collaboration of several specialists and the laboratory, and the time of implantation for the patient prior to the implant implantation (Razmi et al 2010), which would increase the patient's satisfaction. Dental services are always time-consuming due to the special circumstances. Implanting will naturally be more time consuming due to the collaboration of several specialists and lab. This is necessary to tell the patient at the beginning of treatment. Explaining the patient in addition to patients about the collaboration reduces their expectations, can also increase patient satisfaction from work.

Also, the findings showed that approximately $90 \%$ of total satisfaction in patients was well evaluated, and only $10 \%$ of the participants had a moderate overall satisfaction rate. The results of this study were consistent with the results of studies by Pjetursson et al. (2005), Levi et al. (2003), Yi et al. (2001) and Riesmannchian et al. (2007). In their studies, they reported total satisfaction in patients who had implants, including satisfaction with function, beauty, cost, and acceptable levels (Razmi et al 2010) and (Yi et al 2001) and (Rismanchian et al 2007) and (Haji et al 2010). The findings also reported the equal overall satisfaction in male patients and female patients, and did not show any difference between the satisfaction of women and men. It can be said that the most important issue at the end of dental care is the patient's satisfaction. Although the work process and services provided by the dentist may be confirmed, it is more important than the patient's own satisfaction, and it should be noted that satisfaction is a mental issue. In the current study, the satisfaction of implant implants was reported, which indicates that dentists have been able to achieve a satisfactory level of satisfaction at all stages. In all studies, overall satisfaction has always been reported with high rates. This may lead to an increase in implant implants in Iran and other countries in recent years.

\section{CONCLUSION}

According to the mentioned materials, it can be said that dental services in the field of implanting have been able to achieve satisfactory patient satisfaction. Implanting has been able to satisfy patients in the issue of satisfaction with performance, cost, and satisfaction. Only on the work process the patients were dissatisfied while it should be noted that the dentist needed to justify the patient from the beginning of the implant implantation timeliness, the steps required, the need for several specialists and the laboratory to work together, which could moderate the patient's expectations. This will increase patient satisfaction. It should be noted that satisfaction is a mental issue and dentists have to meet the expectations of the patient, especially patients with unreasonable expectations and many expectations of implant implantation treatments, at the beginning of the treatment so that they can increase the level of satisfaction of the patient. 


\section{REFERENCES}

Adell, R., Lekholm, U., Rockler and Brånemark, P.I., 1981. A 15 -year study of osseointegrated implants in the treatment of the edentulous jaw. International journal of oral surgery, 10(6), pp.387-416.

Anner, R., Better, H. and Chaushu, G., 2005. The clinical effectiveness of $6 \mathrm{~mm}$ diameter implants. Journal of periodontology, 76(6), pp.1013-1015.

Awad, M.A., Lund, J.P., Shapiro, S.H., Locker, D., Klemetti, E., Chehade, A., Savard, A. and Feine, J.S., 2003. Oral health status and treatment satisfaction with mandibular implant overdentures and conventional dentures: a randomized clinical trial in a senior population. International Journal of Prosthodontics, 16(4).

Behneke, A., Behneke, N. and d Hoedt, B., 2002. A 5-year longitudinal study of the clinical effectiveness of ITI solid-screw implants in the treatment of mandibular edentulism. International Journal of Oral and Maxillofacial Implants, 17(6), pp.799-810

De Bruyn, H. and Collaert, B., 1994. The effect of smoking on early implant failure. Clinical oral implants research, 5(4), pp.260-264.

Haji F, Rezaei M, provincial N, royal person, the name, auction, Afshin, Mhrshadyan, M., 2010. Patient satisfaction survey of dental clinics of Islamic Azad University in Tehran in 1387. Journal of Dental Science / Volume VII / No. III, pp: 26-32.

Hobo, S., Ichida, E. and Garcia, L.T., 1989. Osseointegration and occlusal rehabilitation. Quintessence Pub Co.

Jeon, J.H., Min, H.H. and Kim, Y.S., 2014. Relationship between satisfaction of dental service, value quality, and reuse intention. Journal of Korean society of Dental Hygiene, 14(5), pp.765-773.

Karoussis, I.K., Salvi, G.E., Heitz-Mayfield, L.J., Brägger, U., Hämmerle, C.H. and Lang, N.P., 2003. Long-term implant prognosis in patients with and without a history of chronic periodontitis: a 10-year prospective cohort study of the ITI ${ }^{\circledR}$ Dental Implant System. Clinical oral implants research, 14(3), pp.329-339.
Lekholm, U., Gunne, J., Henry, P., Higuchi, K., Lindén, U., Bergstrom, C. and Steenberghe, D.V., 1999. Survival of the Brånemark implant in partially edentulous jaws: a 10-year prospective multicenter study. International Journal of Oral and Maxillofacial Implants, 14(5), pp.639-645.

Lindquist, L.W., Carlsson, G.E. and Jemt, T., 1997. Association between marginal bone loss around osseointegrated mandibular implants and smoking habits: a 10-year follow-up study. Journal of dental research, 76(10), pp.1667-1674.

Pjetursson, B.E., Karoussis, I., Bürgin, W., Brägger, U. and Lang, N.P., 2005. Patients' satisfaction following implant therapy. Clinical oral implants research, 16(2), pp.185-193.

razmi, H., Talari, MJ., 1996. Assessment of patient satisfaction in the School of Dentistry, Tehran University of Medical Science Journal of Islamic Dental Association. Dandnpzshkan / Volume 17 / Issue 2, Summer 1384, pp: 82-89

Rismanchian, M, Akbar F., 2007. Clinical and radiographic evaluation of patients treated with ITI implants and assess their satisfaction. Journal of Isfahan Dental School, pp: 112-117.

Saha, A., Dutta, S., Vijaya, V. and Rajnikant, N., 2013. Awareness among patients regarding Implants as a treatment option for replacement of missing teeth in Chattisgarh. Journal of international oral health: JIOH, 5(5), p.48.

Satpathy, A., Porwal, A., Bhattacharya, A. and Sahu, P.K., 2011. Patient awareness, acceptance and perceived cost of dental Implants as a treatment modality for replacement of missing teeth: A survey in Bhubaneswar and Cuttack. International Journal of Public Health Dentistry, 2(1), pp.1-7.

Wheeler, S., 2003. Use of the Frialit-2 Implant System in private practice: a clinical report. International Journal of Oral \& Maxillofacial Implants, 18(4).

Yao, J., Tang, H., McGrath, C.P.J., Gao, X. and Mattheos, N., 2014. Patients' expectations to dental implant: a systematic review. Journal of Dental Research.

Yi, S.W., Carlsson, G.E., Ericsson, I. and Kim, C.K., 2001. Patient evaluation of treatment with fixed implant-supported partial dentures. Journal of oral rehabilitation, 28(11), pp.998-1002. 